\title{
3D WEB VISUALIZATION OF ENVIRONMENTAL INFORMATION - INTEGRATION OF HETEROGENEOUS DATA SOURCES WHEN PROVIDING NAVIGATION AND INTERACTION
}

\author{
L. Herman ${ }^{\text {a }}$, T. ̌̌ezník ${ }^{\text {a }}$ \\ ${ }^{a}$ Department of Geography, Faculty of Science, Masaryk University, Kotlářská 2, 61137 Brno, The Czech Republic - \\ herman.lu@mail.muni.cz, tomas.reznik@sci.muni.cz
}

Commission II, WG II/6

KEY WORDS: 3D visualization, environmental information, interaction, navigation, web cartography, X3DOM.

\begin{abstract}
:
3D information is essential for a number of applications used daily in various domains such as crisis management, energy management, urban planning, and cultural heritage, as well as pollution and noise mapping, etc. This paper is devoted to the issue of 3D modelling from the levels of buildings to cities. The theoretical sections comprise an analysis of cartographic principles for the $3 \mathrm{D}$ visualization of spatial data as well as a review of technologies and data formats used in the visualization of 3D models. Emphasis was placed on the verification of available web technologies; for example, X3DOM library was chosen for the implementation of a proof-of-concept web application. The created web application displays a 3D model of the city district of Nový Lískovec in Brno, the Czech Republic. The developed 3D visualization shows a terrain model, 3D buildings, noise pollution, and other related information. Attention was paid to the areas important for handling heterogeneous input data, the design of interactive functionality, and navigation assistants. The advantages, limitations, and future development of the proposed concept are discussed in the conclusions.
\end{abstract}

\section{INTRODUCTION}

The 3D visualization of spatial data is nowadays used in many fields and with regard to many issues. 3D models and visualizations can be applied to the analysis of the current state, the reconstruction of the past, the prediction of future developments, and the choice of multiple options for future development within planning. 3D models may be used by experts and laymen alike. 3D visualization also has the ability to assist in dealing with problems on different scales - from the global and regional levels to the local level involving towns and cities (Konečný, 2011).

Possible applications for 3D models and visualization constitute a very broad spectrum. The use of $3 \mathrm{D}$ visualisation has been described, for example, in following areas, including:

- virtual tourism (Laakso, 2003; Ding, 2011),

- 3D cadastre (Shojaei et al., 2013),

- the documentation and preservation of cultural heritage (Jedlička et al., 2010; Popelka and Brychtová, 2012),

- crisis management (Bandrova et al., 2010; Kemec et al., 2010) and the visualization of floods (Roy and Coors, 2011),

- urban planning (Ki, 2011) and visibility analysis (Guney et al., 2012),

- meteorology and research of urban heat islands (Congote et al., 2012; San Jose et al., 2012),

- the energy demands of buildings (Strzalka et al., 2011) and analysis of the solar potential of buildings (Hofierka and Zlocha, 2012),

- noise mapping (Law et al., 2011; Herman and Ǩezník, 2013),

- unmanned aerial vehicles (Ǩezník et al., 2013),
- geographical data in general (̌̌ezník, 2013).

\section{THEORETICAL BACKGROUND}

Still too little is known about how 3D visualizations may be used to full effect. Some authors, e.g. Voženílek (2005), argue that $3 \mathrm{D}$ visualization is capable of presenting large amounts of complex information to wider audiences, including those with little or no cartographical or GIS experience.

Shepherd (2008) describes the specific benefits of the 3D visualization of spatial data. The main advantages are the existence of more space for displaying additional data variables, the resolving of issues relating to hidden symbols, and access to a more familiar view of space. On the other hand, both Shepherd (2008) and Jobst and Germanchis (2007) also mention possible problems that may arise during $3 \mathrm{D}$ visualization. These include the occlusion of objects in a 3D scene, perspective distortion, the existence of countless scales within one view, and incomparable geometries of objects.

Schmidt and Delazari (2011) consider disorientation as the most common problem associated with virtual 3D space. They provide a list of navigation assistants that are intended to prevent disorientation (e.g. cardinal points on the edge of the model, a north arrow, or grid reference). An overview map may also serve the same purpose and enable users to gain knowledge of the relative layout and distances between objects (Ware and Plumlee, 2005). This paper focuses on the practice of implementing the abovementioned navigation assistants.

Careful design of the GUI (Graphical User Interface) is an issue which is as important as the above-mentioned problems associated with interactive 3D. Schnürer et al. (2015) compare 
different types of GUI. They are defined mainly by the positioning of the legend, buttons, and other controls. Individual variants of the compared GUIs are based on existing multimedia applications (e.g. YouTube) or 2D web maps (GoogleMaps). In this study, we also use a GUI inspired by 2D map portals, which can be expected to be sufficiently intuitive for most users.

Jahnke et al. (2009) see the GUI from another perspective. They distinguish between photorealistic and non-photorealistic visualization. Both approaches can be used individually to visualize environmental information or they can be combined (Bleisch, 2012). Photorealistic visualization is preferable in some areas (e.g. urban planning or the documentation of cultural heritage), while for some areas non-photorealistic is sufficient (the energy demands of buildings or noise mapping). Our particular focus is on the verification of non-photorealistic visualization.

\section{OVERVIEW OF RELATED TECHNOLOGIES}

Technologies that are used in 3D visualization include graphical formats and software libraries for 3D rendering, as well as GIS standards and services.

\subsection{D data formats}

Probably the oldest most widespread format for interactive 3D computer graphics is VRML (Virtual Reality Modelling Language). VRML is a text file format in which $3 \mathrm{D}$ geometry can be specified along with surface colour, texture, transparency, and other properties. X3D (Extensible 3D) is another open standard file format based on XML for the description of spatial scenes. Essentially, it is recognized as the successor to VRML. COLLADA is also designed to store 3D objects and animations as it has similar capabilities to VRML and X3D and also the structure of XML (Swanson, 1999; Behr et al., 2009).

GML (Geography Markup Language) is an XML grammar defined by the Open Geospatial Consortium (OGC) to express geographical features. GML was originally only 2D; however, since version 3.0, it has also been possible to manage 3D data. CityGML is an application schema for GML version 3.1.1 for the storage and exchange of virtual 3D city models. KML (Keyhole Markup Language) is primarily intended for the publication and distribution of geographic data. The format is primarily used for the mapping applications Google Maps and Google Earth. KML 2.2 was adopted in 2008 as an OGC standard (Kolbe, 2009).

\subsection{Web services}

3D data may also be published through web services. 3D spatial data can be accessed and manipulated through the Web Feature Service (WFS). The 3D Portrayal service (3DPS) is a service definition for a direct view of desired 3D data. 3DPS is capable of containing both 3D graphics (e.g. X3D) and raster images that have previously been rendered on the server side. The OGC (Open Geospatial Consortium) is currently working on the adoption of this service definition proposal (Coors et al., 2015).

It should also be emphasized that probably the most widespread web service, WMS (Web Map Service), cannot be used for the distribution or presentation of 3D data, since it only provides 2D graphics. Nevertheless, 2D data may be used as a bitmap texture in 3D models. Such an option was also verified in this study.

\subsection{D Rendering in a web browser}

A broad spectrum of technologies is available for rendering the above-described data formats, which run on the client side. In addition to thick clients, which are standalone applications such as Google Earth, there are a number of techniques for displaying 3D data using a simple web browser. Many of them use plug-ins.

\begin{tabular}{|c|c|c|}
\hline library & licence & type \\
\hline 3DGIS cityvu & Freeware & 3D scene \\
\hline 3DIS WebViewer & Freeware & 3D scene \\
\hline Cortona 3D viewer & free and commercial & 3D scene \\
\hline Adobe Flash plug-in & Freeware & 3D scene \\
\hline $\begin{array}{l}\text { Adobe Acrobat } \\
\text { Reader plug-in }\end{array}$ & Freeware & 3D scene \\
\hline $\begin{array}{l}\text { Google Earth plug- } \\
\text { in }\end{array}$ & Freeware & virtual globe \\
\hline Java FX & Open Source & 3D scene \\
\hline JebGL & MIT & 3D scene \\
\hline JOGL & MIT & 3D scene \\
\hline $\begin{array}{l}\text { Microsoft } \\
\text { Silverlight }\end{array}$ & Freeware & 3D scene \\
\hline NASA World Wind & $\begin{array}{l}\text { NASA Open Source } \\
\text { Agreement v1.3 }\end{array}$ & virtual globe \\
\hline XNavigator & $\begin{array}{l}\text { GNU General } \\
\text { Public License } 2\end{array}$ & virtual globe \\
\hline
\end{tabular}

Table 1. Overview of plug-in based solutions for the visualization of $3 \mathrm{D}$ spatial data

3D models can be displayed in a web environment using Flash plug-in, version 11.0 or higher, or Microsoft Silverlight technology, version 3.0 or higher (Behr et al., 2009). Plug-ins are also used for the implementation of virtual globes, for example NASA World Wind, which is in the Java language. A list of technologies using plug-ins is given in Tab. 1; the virtual globes are distinguished.

Today, however, preference is given to technologies which work without plug-ins. These solutions are usually built on HTML5 and JavaScript library WebGL. One of many examples of libraries based on WebGL is X3DOM, which uses the data structure of the X3D format. The advantage of this library is broad support in Web browsers. Practical aspects of the use of the X3DOM library for the 3D visualization of detailed models of cities are described, for example, by Herman et al. (2015).

Other libraries similar to X3DOM are, for example, SpiderGL, which also uses data in a COLLADA file structure (Di Bennedetto et al., 2011); XML3D; SceneJS; and Three.js. A comprehensive list of these libraries is presented in Tab. 2. Further overviews of the various web technologies and libraries used in 3D data visualization are provided by Behr et al. (2009), Behr et al. (2011), and Lienert et al. (2012).

The X3DOM library was chosen for the implementation of the pilot study. Its wide support in Web browsers was the main motivation, as well as the availability of associated software for 
creating 3D input data and the accessibility of documentation and relevant examples.

\begin{tabular}{|c|c|c|c|}
\hline library & language & licence & type \\
\hline ESRI City & & & \\
\hline Engine Web & JS & $\begin{array}{l}\text { Free and } \\
\text { commercial }\end{array}$ & 3D scene \\
\hline $\mathrm{C} 3 \mathrm{DL}$ & JS & MIT & 3D scene \\
\hline Cesium & JS, C\# & Apache 2.0 & virtual globe \\
\hline CooperLicht & JS & $\begin{array}{l}\text { Free and } \\
\text { commercial }\end{array}$ & 3D scene \\
\hline GLGE & JS & BSD & 3D scene \\
\hline Oak3D & JS & Own, free & 3D scene \\
\hline OpenWebGlobe & JS, C++ & MIT & virtual globe \\
\hline OSGJS & JS & GNU GPL 3 & 3D scene \\
\hline PhiloGL & JS & MIT & 3D scene \\
\hline Ready Map & JS & GNU LGPL & virtual globe \\
\hline SceneJS & JS & $\begin{array}{l}\text { MIT or } \\
\text { GNU GPL } 2\end{array}$ & 3D scene \\
\hline SpiderGL & JS & GNU GPL 2 & 3D scene \\
\hline WebGL Earth & JS & GNU GPL 3 & virtual globe \\
\hline three.js & JS & MIT & 3D scene \\
\hline X3DOM & JS & $\begin{array}{l}\text { MIT or } \\
\text { GNU GPL } 3\end{array}$ & 3D scene \\
\hline XML3D & JS & Own, free & 3D scene \\
\hline
\end{tabular}

Table 2. Overview of WebGL-based programming libraries for the $3 \mathrm{D}$ visualization of spatial data

\section{PILOT STUDY}

The technologies described in this paper were verified on the example of the city district of Nový Lískovec in Brno, the Czech Republic.

\subsection{Design}

An important aspect in the processing of the application was to create a user-friendly interface with functionality inspired by a $2 \mathrm{D}$ interactive map. The main function is interactive movement and navigation in a 3D scene and support for non-interactive movement. A closely related function is support for determining position and orientation in the $3 \mathrm{D}$ scene.

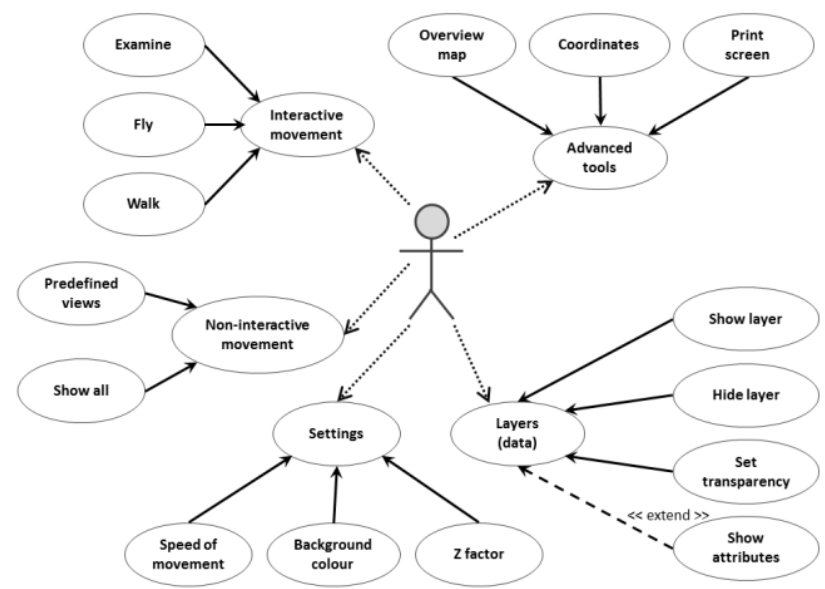

Figure 1. Use case diagram of the developed application
The 3D scene will be designed so that it is clear and simple; more details can be displayed only on demand. It should also deal with the overlap of $3 \mathrm{D}$ objects. The hierarchy of the proposed functions is shown in Fig. 1.

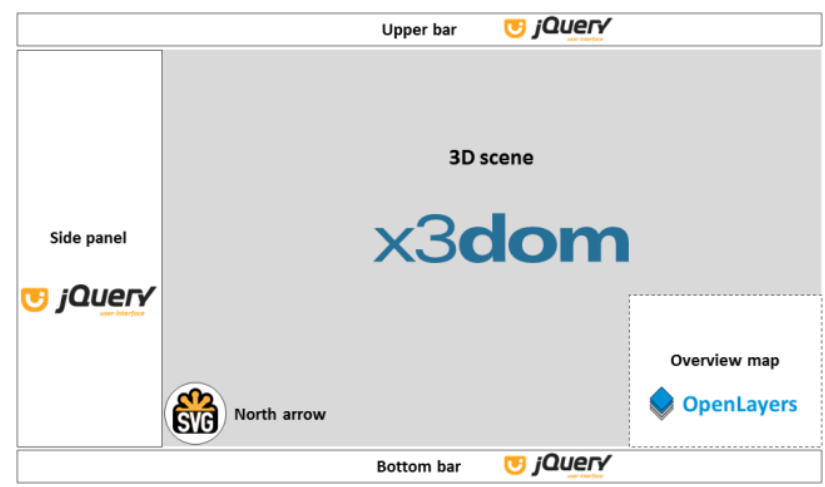

Figure 2. Proposal of layout of developed application

The proposal for the layout is shown in Fig. 2 and is formed by the upper bar, the side panel, the bottom bar, and the $3 \mathrm{D}$ scene. The upper bar contains various function buttons. The side panel lists layers with the legend, predefined views, and the setting of the 3Dscene. Individual features represent HTML elements serviced by JavaScript and jQuery UI library. The bottom rail consists of $\mathrm{X}$ and $\mathrm{Y}$ coordinates as well as a button for displaying the overview map.

Advanced issues which should be resolved if $3 \mathrm{D}$ visualization is to be equivalent to $2 \mathrm{D}$ interactive web maps are described in more detail below.

\subsection{Input data}

Input data are represented by the terrain model and 3D models of 823 buildings (at Level of Detail 1 - extruded footprints). The 3D geometry of the buildings originally came from stereophotogrammetry and was stored in CityGML format. The terrain data (contour lines, break lines and mass points) and also the street network are parts of ZABAGED, the official Czech topographic database.

Two different sources of noise maps were available for the studied area. The first shows the spatial distribution of equivalent continuous sound pressure levels at night (22:00 6:00) and during the daytime $(6: 00-22: 00)$. They were calculated according to conditions in 2004 and were stored locally as PNG (Portable Network Graphics) raster files.

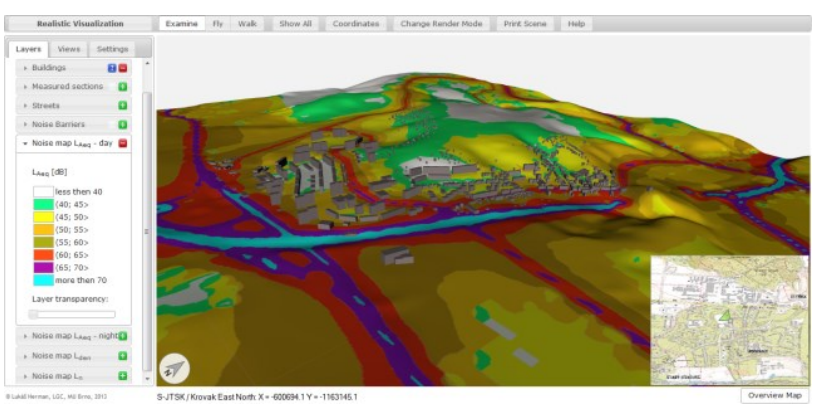

Figure 3. An example of the graphical user interface of the developed application 
The second shows the spatial distribution of day-evening-night noise indicator and the long-term average sound level during night-time $(22: 00-6: 00)$. This second source of sound maps was valid for the year 2007 and was available via WMS. Decibels $(\mathrm{dB})$ are the units used in all four variants of noise maps, i.e. noise maps based on two sources, with two indicators for each source. All noise maps were calculated for a level of 4 meters above the terrain.

\subsection{Transformation and integration of different data sources}

The terrain model, street network, and local noise maps were transformed in ArcGIS 10.1 software. They were exported from the ArcScene module to VRML files and then converted into X3D (in View3dScene freeware). The processing of these data is shown in Fig. 4. The data in X3D format can be fed directly into web pages, or a user can refer to them when using the $\mathrm{X} 3 \mathrm{DOM}$ tag Inline (this option has been used in our case).

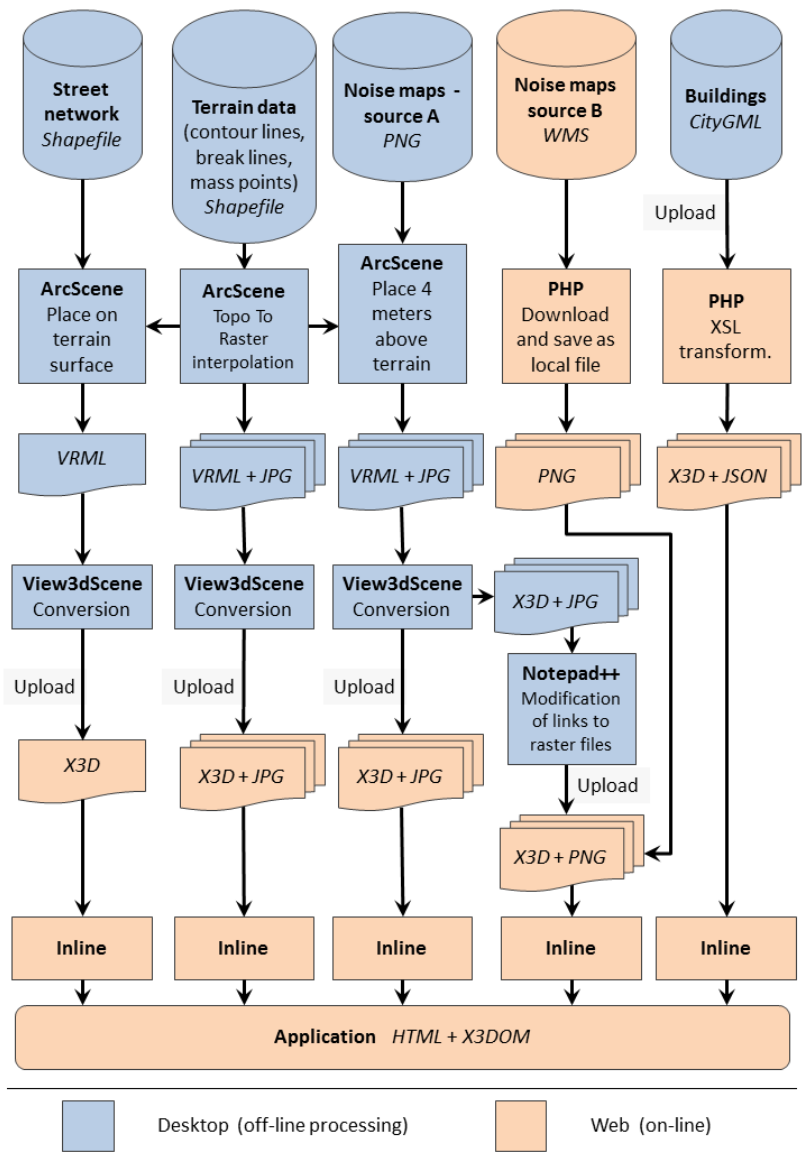

Figure 4. Workflow of data processing

It was necessary to use simple PHP (Hypertext Preprocessor) scripts in order to support on-the-fly conversions of other XML formats or the direct loading of web services in the proposed application. The developed CityGML models of buildings were transformed through syntaxes in PHP and XSL (eXtensible Stylesheet Language). The principles of the XSL transformation of 3D spatial data are described in more detail in Herman and Řezník (2013). In the proof-of-concept application, the PHP script also serves to create JSON (JavaScript Object Notation) file containing attributes and to download data from the WMS (this noise map is visible in Fig. 5). The concrete form of the cartographic visualization (value scale, colour scheme) of noise maps is taken from WMS data. Cartographic visualization of the other two noise maps loaded from locally stored PNG tiles was not modified (shown in Fig. 3).

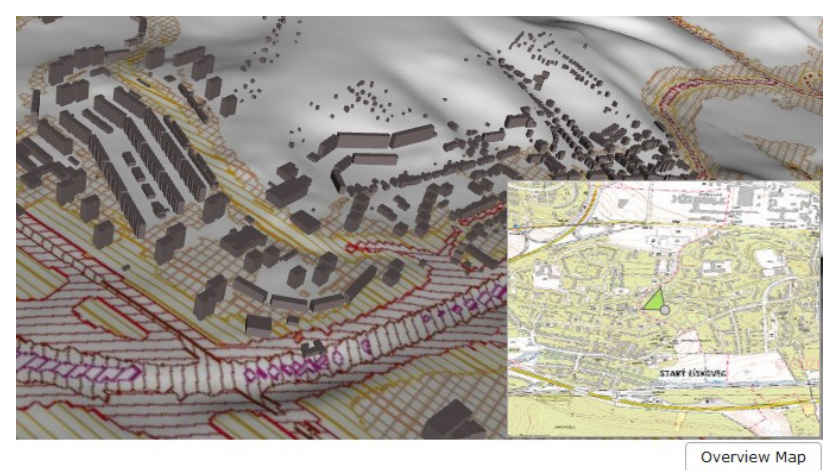

Figure 5. Detail of 3D scene with noise map loaded form WMS and overview map

\subsection{Implementation of navigation tools}

The implementation of various navigation assistants, as emphasized above, was an important feature on top of data integration. The implementation was facilitated by the availability of functions for obtaining the current position and orientation of the virtual camera in the X3DOM API (Application Programming Interface).

Functions called "evt.position" and "evt.orientation" were used to obtain these data. Actual coordinates are displayed in the scope of the HTML code. The SVG (Scalable Vector Graphics) format is used to design the interactive North arrow. SVG is stored directly in the HTML code, just as the X3D scenes (see Fig. 6). The orientation of the virtual camera affects the rotation of the North arrow. It is necessary to know the value at the $\mathrm{Y}$ axis, since the rotation is defined by the right hand rule.

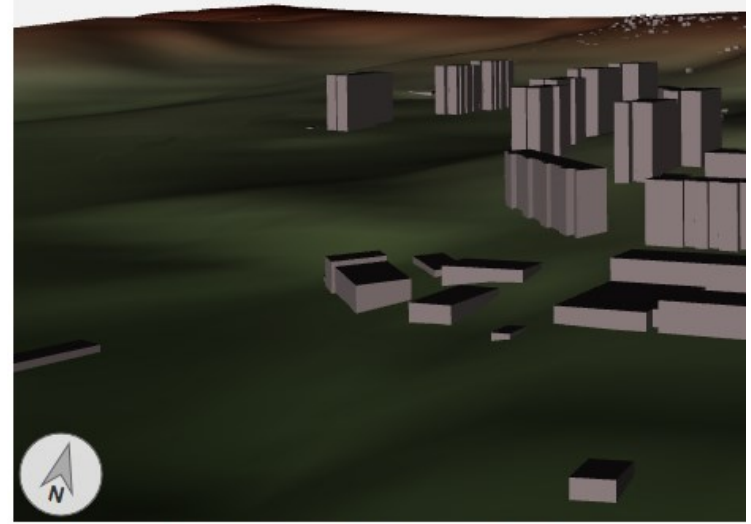

S-JTSK $/$ Krovak East North: $X=-602248.8 Y=-1162924.6$

Figure 6. North arrow and coordinates of the virtual camera

The connection with the overview map follows the same principles as the coordinate display. A 3D scene is tied to a $2 \mathrm{D}$ map in such a way that the center of the map corresponds to the coordinates of the position of a virtual camera. The location of the camera is expressed by means of symbols created in SVG (see Fig. 5). An overview map is created when using the OpenLayers library. 


\subsection{Interactive functionality}

Other interactive functions were implemented by the jQuery library. A legend for the displayed data was placed in the right vertical panel. Control panels were defined allowing users to switch between layers (e.g. noise maps) and sliders were created to enable users to set the transparency of the layers (see Fig. 7). Transparency avoids the occlusion of 3D features or layers.

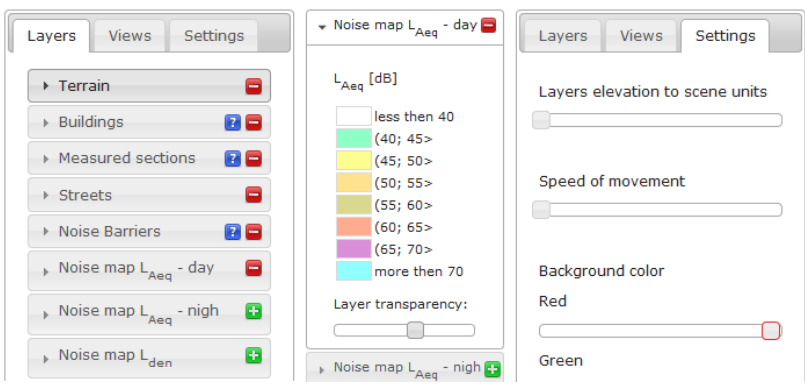

Figure 7. Detail of the right panel (from the left) - layer switcher, legend, and scene setting

The attributes of each element (building) are available in the main window of the 3D scene after clicking on it (see Fig. 8 left). The coordinates of the selected point may be previewed as well (see Fig. 8 - right).
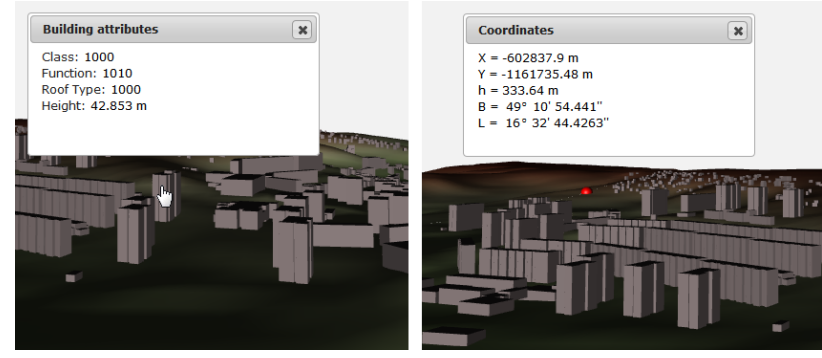

Figure 8. Popup windows - attributes of selected building (left) and coordinates upon clicking on the respective item

\section{DISSCUSION}

Regarding cartographic visualization, the developed software is not dependent on the visualization(s) of underlying data. Cartographic visualization should be developed separately for each application and is not directly re-distributable, since it is written directly in the X3D source code. Rules for cartographic visualization are defined through $\mathrm{X} 3 \mathrm{D}$ attributes and involve similar principles as the visualization of HTML pages or SVG files. In other words, within the developed software presented in this paper, we may define, for example, a standardized cartographic visualization for noise maps as well as photorealistic visualization.

Different color scales are used to visualize noise maps. On the basis of their application and testing, it was found that it is necessary to work judiciously with a color value as a graphic variable. The design and optimization of symbology for $3 \mathrm{D}$ visualization is one of the areas which would benefit from further research.

The sizes of final data layers were analyzed, as well as the speed of rendering 3D web scenes and responding to XHR requirements with respect to loading $3 \mathrm{D}$ files. The results are summarized in Tab. 3. The performance of the developed application has been successfully tested in the web browsers Mozilla Firefox, Google Chrome, and Opera.

\begin{tabular}{|l|r|r|r|}
\hline & $\begin{array}{c}\text { number } \\
\text { of } \\
\text { requests }\end{array}$ & $\begin{array}{c}\text { speed of } \\
\text { responses } \\
\text { [s] }\end{array}$ & $\begin{array}{c}\text { size of } \\
\text { loaded } \\
\text { data } \\
\text { [MB] }\end{array}$ \\
\hline $\begin{array}{l}\text { 3D scene with noise } \\
\text { map - implicit layers }\end{array}$ & 56 & 4.96 & 8.8 \\
$\begin{array}{l}\text { 3D scene with noise } \\
\text { maps - all layers }\end{array}$ & 57 & 4.90 & 12.6 \\
\hline
\end{tabular}

Table 3. Testing the loading speed of individual 3D visualizations

\section{CONCLUSIONS AND FUTURE WORK}

The presented proof-of-concept application was established in order to verify the possibility of open web-based $3 \mathrm{D}$ visualization. It should be emphasized that the openness relies on the data used as well as the final application. Proprietary software - in this study, ArcGIS 10.1 - was used for the proofof-concept stage. However, this does not preclude the use of any open source as well as proprietary software for processing data and the development of the final application. X3D support for development software is the only constraint.

To sum up, the following major advantages of $3 \mathrm{D}$ visualization based on X3DOM and other JavaScript libraries were identified:

- it enables user-friendly 3D visualization based on Web technologies;

- it does not require any new software or plug-in on the client or server sides to be installed;

- it enables the $3 \mathrm{D}$ visualization of heterogeneous data from the environmental domain and beyond;

- it demonstrates that it is possible to create interactive tools and navigation assistants for virtual $3 \mathrm{D}$ environments;

- it shows that the functionality common to $2 \mathrm{D}$ interactive web maps may also be transferred to $3 \mathrm{D}$ visualizations;

- it is based on a combination of open JavaScript libraries and may therefore be further modified or easily extended.

The developed proof-of-concept application is freely available to interested persons under a BSD license.

Future work will follow two directions - the integration of data from specific sources and usability research of various navigational assistants and tools. Standardized data have considerable potential in this respect, especially those published under the European INSPIRE Directive (2007/2/EC). In the future, X3DOM should be used as an interface for the OGC 3D Portrayal service. Other types of standardized data can also be displayed within the $3 \mathrm{D}$ scene - for example, data processed according to OGC Sensor Web Enablement (SWE). Two basic requirements are placed on data which should be integrated into the 3D scene; they should have a 3D spatial reference and be in a format that can be accessed on the Web (e.g. XML-based formats, CSV or JSON).

Regarding usability research, speed and accuracy should be examined when comparing (non-)available navigation assistants. Various representations of position and orientation may also be examined - for instance, through eye-tracking 
techniques. Orientation may be expressed, for example, by means of a north arrow or a symbol for the virtual camera in the overview map. Some tasks such as determining the position and orientation of a user are insoluble without the use of navigation assistants (e.g. a north arrow).

\section{ACKNOWLEDGEMENTS}

This research was funded by Grant No. MUNI/A/1370/2014, 'Global environmental changes in time and space' and Grant No. MUNI/FR/1760/2014, 'Innovation of the course Z8311 3D modeling and visualization', both awarded by Masaryk University, Czech Republic.

\section{REFERENCES}

Bandrova, T., Zlatanova, S., Konečný, M., 2012. ThreeDimensional Maps for Disaster Management. ISPRS Annals of the Photogrammetry, Remote Sensing and Spatial Information Sciences. Vol. 4, Melbourne, Australia, pp. 245-250.

Behr, J., Eschler, P., Jung, Y., Zöllner, M., 2009. X3DOM - A DOM-based HTML5/ X3D Integration Model. In: Proceedings of Web3D 2009: The 14th International Conference on Web3D Technology, Web3D 2011, Darmstadt, Germany.

Behr, J., Jung, Y., Drevensek, T., Aderhold, A., 2011 Dynamic and Interactive Aspects of X3DOM. In: Proceedings of the 16th International Conference on $3 D$ Web Technology, Paris, France.

Bleisch, S., 2012. 3D Geovisualization - Definition and Structures for the Assessment of Usefulness. ISPRS Annals of the Photogrammetry, Remote Sensing and Spatial Information Sciences. Vol. 2, Melbourne, Australia, pp. 129-134.

Congote, J., Moreno, A., Kabobgo, L., Perez, J. L., San Jose, R., Ruiz, O., 2012. Web Based Hybrid Volumetric Visualisation of Urban GIS Data - Integration of 4D Temperature and Wind Fields with LoD-2 CityGML Models. In: Leduc, T., Moreau, G., Billen, R. (eds.) Usage, Usability, and Utility of $3 D$ City Models - European COST Action TU0801, Nantes, France.

Coors, V., Hagedorn, B., Thum, S., 2015. OGC 15-001 3D Portrayal Implementation Standard. 76 p. http://www.opengeospatial.org/pressroom/pressreleases/2165 (29 May 2015).

Di Benedetto, M., Corsini, M., Scopigno, R., 2011. SpiderGL: A Graphics Library for 3D Web Applications. ISPRS Archives of the Photogrammetry, Remote Sensing and Spatial Information Sciences, Vol. XXXVIII-5/W16, Trento, Italy, pp. 467-474.

Ding, Y. C., 2010. Using Digital Earth to create online scientific reality tourist guides to tourist attractions in Taiwan, China. In: Proceedings SPIE 7840, Sixth International Symposium on Digital Earth: Models, Algorithms, and Virtual Reality, Beijing, China.

Guney, C., Girginkava, S. A., Cagdas, G., Yavuz, S., 2012. Tailoring a Geomodel for Analyzing an Urban Skyline. Landscape and Urban Planning, Vol. 105, No. 1-2, pp. 160173.

Herman, L., Řezník, T., 2013. Web 3D Visualization of Noise Mapping for Extended INSPIRE Buildings Model. In: Hřebíček, J., Schimak, G., Kubásek, M., Rizzoli, A. E. (eds.)
Environmental Software Systems. Fostering Information Sharing, Springer, pp. 414-424.

Herman L., Kýnová A., Russnák J., Řezník T., 2015. Comparison of Standard- and Proprietary-Based Approaches to Detailed 3D City Mapping. In Brus J., Vondraková A., Voženílek V. (eds.) Modern Trends in Cartography, Springer, pp. 131-144.

Hofierka, J., Zlocha, M., 2012. New 3-D Solar Radiation Model for 3-D City Models. Transactions in GIS. Vol. 16, No. 5, pp. 681-690.

Jahnke M., Meng L., Kyprianidis J. E., Döllner J., 2009. Nonphotorealistic Visualizations on Mobile Devices and Usability Concerns. In Lin H., Batty M. (eds.) Virtual Geographic Environments, Science Press, pp. 168-181.

Jedlička, K., Čerba, O., Hájek, P., 2013. Creation of Information-Rich 3D Model in Geographic Information System - Case Study at the Castle Kozel. In: Informatics, Geoinformatics and Remote Sensing, Conference Proceedings volume I, Albena, Bulgaria, pp. 685-692.

Jobst, M., Germanchis, T., 2007. The Employment of 3D in Cartography - An Overview. In: Cartwright, W., Peterson, M. P., Gartner, G. (eds.) Multimedia Cartography, Springer, pp. 217-228.

Kemec, S., Duzgun, S., Zlatanova, S., Dilmen, D. I., Yalciner, A. C., 2010. Selecting 3D Urban Visualisation Models for Disaster Management: Fethiye Tsunami Inundation Case. In: Proceedings of the 3rd International Conference on Cartography and GIS, Nessebar, Bulgaria.

Ki, J., 2011. Developing a Geospatial Web-GIS System for Landscape and Urban Planning. International Journal of Digital Earth. Vol. 6 No. 6, pp. 580-588.

Kolbe, T. H., 2009. Representing and exchanging 3D city models with CityGML. In Lee, J., Zlatanova, S. (eds.) 3D GeoInformation Sciences, Springer, pp. 15-31.

Konečný, M., 2011. CARTOGRAPHY: Challenges and Potentials in Virtual Geographic Environments Era. Annals of GIS. Vol. 17, No. 3, pp. 135-146.

Laakso, K., Gjesdal, O., Sulebak, J. R., 2003. Tourist information and navigation support by using 3D maps displayed on mobile devices. In: Proceedings of Mobile HCI Workshop on Mobile Guides, Udine, Italy, pp. 34-39.

Law, C., Lee, C., Lui, A. S., Yeung, M. K., Lam, K., 2011. Advancement of Three-Dimensional Noise Mapping in Hong Kong. Applied Acoustics. Vol. 72, No. 8, pp. 534-543.

Lienert, C., Jenny, B., Schnabel, O., Hurni, L., 2012. Current Trends in Vector-Based Internet Mapping: A Technical Review. In Peterson, M. P. (ed.) Online Maps with APIs and Web Services, Springer, pp. 23-36.

Popelka, S., Brychtová, A., 2012. The Historical 3D Map of Lost Olomouc Fortress Creation. In: Svobodová, H. (eds.) Proceedings of the 19th International Conference on Geography and Geoinformatics: Challenge for Practise and Education. Brno, Czech Republic.

Roy, D. C., Coors, V., 2011. 3D Web-based GIS for Flood Visualization and Emergency Response. In: Society of Petroleum Engineers - 73rd European Association of Geoscientists and Engineers Conference and Exhibition 2011 Incorporating SPE EUROPEC 2011, Vienna, Austria. 
Rezník, T., 2013. Geographic information in the age of the INSPIRE Directive: discovery, download and use for geographical research. Geografie. Vol. 118, No. 1, pp. 77-93.

Řezník, T., Horáková, B., Szturc, R., 2013. Geographic Information for Command and Control Systems Demonstration of Emergency Support System. In: Zlatanova, S., Dilo, A., Peters, R., Scholten, H. (eds.) Intelligent Systems for Crisis Management: Geo-information for Disaster Management (GI4DM) 2012, Springer, pp. 263-275.

San Jose, R., Perez, J. L., Gonzalez, R. M., 2012. Advances in 3D Visualization of Air Quality Data. In: Leduc, T., Moreau, G., Billen, R. (eds.) Usage, Usability, and Utility of 3D City Models - European COST Action TU0801, Nantes, France.

Schmidt, M. A. R., Delazari, L. S., 2011. User Testing with Tools for 3D Visual Navigation. In: Proceedings of the 25th International Cartographic Conference, Paris, France.

Schnürer, R., Sieber, R., Çöltekin, A., 2015. The Next Generation of Atlas User Interfaces: A User Study with "Digital Natives”. In: Brus J., Vondráková, A., Voženílek V. (eds.) Modern Trends in Cartography, Springer, pp. 23-36.

Shepherd, I., 2008. Travails in the Third Dimension: A Critical Evaluation of Three Dimensional Geographical Visualization. In: Dodge, M., McDerby, M., Turner, M. (eds.) Geographic Visualization: Concepts, Tools an Applications, Wiley, pp. 199222.

Shojaei, D., Kalantari, M., Bishop, I. D., Rajabifard, A., Aien, A., 2013. Visualization Requirements for 3D Cadastral Systems. Computers, Environment and Urban Systems. Vol. 41, pp. 39-54.

Strzalka, A., Bogdahn, J., Coors, V., Eicker, U., 2011. 3D City modeling for urban scale heating energy demand forecasting. HVAC\&R Research. Vol. 17, No. 4, pp. 526-539.

Swanson, J., 1999. Cartographic Possibilities of VRML. Cartwright, W., Peterson, M. P., Gartner, G. (eds.) Multimedia Cartography, Springer, pp. 181-194.

Voženílek, V., 2005. Cartography for GIS: Geovisualization and Map Communication. 1st ed., Palacký University Olomouc, $142 \mathrm{p}$.

Ware, C., Plumlee, M., 2005. 3D Geovisualization and the Structure of Visual Space. In: Dykes, J., MacEachren, A. M., Kraak, M. J. (eds.) Exploring Geovisualization, Elsevier, pp. 567-576. 